\title{
Photooxidation of 4-chlorophenol sensitised by iron meso-tetrakis(2,6-dichloro-3-sulfophenyl)porphyrin in aqueous solution $\uparrow$
}

\author{
Eliana Silva, ${ }^{a}$ Mariette M. Pereira, ${ }^{* a}$ Hugh D. Burrows, ${ }^{a}$ M. E. Azenha, ${ }^{a}$ Mohamed Sarakha ${ }^{b}$ \\ and Michèle Bolte ${ }^{b}$ \\ ${ }^{a}$ Rua Larga, Departamento de Química, Universidade de Coimbra, 3004-535 Coimbra, \\ Portugal \\ ${ }^{b}$ Laboratoire de Photochimie et Macromoléculaire, URA CNRS 433, Université Blaise-Pascal, \\ Clermont Ferrand, 63177 Aubière Cedex, France.E-mail: mmp@ci.uc.pt
}

Received 30th July 2003, Accepted 7th October 2003

First published as an Advance Article on the web 25th November 2003

\begin{abstract}
The photosensitised degradation of 4-chlorophenol (4-CP) by iron meso-tetrakis(2,6-dichloro-3-sulfophenyl)porphyrin (FeTDCPPS) has been studied in aerated aqueous solution, and is shown to lead to formation of $p$-benzoquinone (BQ) and $p$-hydroquinone (HQ) as main photoproducts. In deaerated solution no $p$-benzoquinone was formed. The photolysis products were identified by high performance liquid chromatography (HPLC) and UV-visible spectroscopy. The photodegradation in aerated solution was also carried out in the presence of sodium azide $\left(\mathrm{NaN}_{3}\right)$ as a singlet oxygen $\left[{ }^{1} \mathrm{O}_{2}\left({ }^{1} \Delta_{\mathrm{g}}\right)\right]$ quencher, and showed a significant decrease in the rate of photolysis, suggesting under these conditions, that Type II sensitisation is one of the dominant mechanisms of 4-CP degradation. Support for this comes from laser flash photolysis and time-resolved singlet oxygen phosphorescence measurements. However, these also show direct reaction between the excited porphyrin and 4-CP, indicating that there are two mechanisms involved in the chlorophenol photodegradation.
\end{abstract}

\section{Introduction}

Chlorinated phenolic compounds are frequently found as pollutants in wastewater, ${ }^{1-3}$ and originate from sources as diverse as the wood-pulp industry, water purification and production of synthetic pesticides, polymers, detergents, etc. The impact caused on environment by these compounds has led to an increasing interest not only in developing new methods for promoting the decomposition of such materials in aqueous medium but also in the identification of their photoproducts. The degradation of phenolic compounds has been extensively studied, ${ }^{4-10}$ although in several systems the catalysts and the main products of oxidation are more toxic than the starting materials.

Increased emphasis is being placed on advanced oxidation processes $(\mathrm{AOP})^{11}$ for water treatment, and for environmental remediation. Photochemical oxidation, particularly using molecular oxygen, is undoubtedly one of the most important of these methodologies, since it does not liberate any additional pollutant. Singlet oxygen is a particularly good candidate for these applications since it is a very reactive species, as can be seen from its applications in areas as diverse as photodynamic therapy for treatment of cancer, ${ }^{12}$ involvement in processes of oxidative stress, ${ }^{13}$ photodegradation of dyes, polymers, alkenes and phenolic compounds. ${ }^{14}$ The development of new synthetic substances capable of efficient production of singlet oxygen, $\left[{ }^{1} \mathrm{O}_{2}\left({ }^{1} \Delta_{\mathrm{g}}\right)\right]$, is currently of great interest. Porphyrins, metalloporphyrins ${ }^{14}$ and phthalocyanines ${ }^{15,16}$ have been shown to be highly effective triplet state photosensitisers capable of producing singlet oxygen with high quantum yields. ${ }^{17,18}$ Further, it is well documented that the presence of chlorine atoms in meso phenyl groups or the presence of central metal atoms in the porphyrin structure increases the quantum yields of $S_{1} \rightarrow T_{1}$ intersystem crossing (isc), and hence triplet state formation of the sensitiser. ${ }^{19,20}$ For example, it has been reported that the triplet quantum yield, $\Phi_{\mathrm{T}}$, for meso-tetrakis(2,6-dichloro-

$\dagger$ Dedicated to Professor Sebastião Formosinho on the occasion of his 60 th birthday. phenyl)porphyrin has a value of 0.995 , while the corresponding singlet oxygen quantum yield, $\Phi_{\Delta}$, is 0.98 . This porphyrin has proved to be an efficient sensitiser for the photooxidation of 1,5-dihydroxynaphthalene to 5-hydroxynaphthoquinone. ${ }^{21}$

However, this porphyrin is only soluble in organic solvents, and for environmental applications it is desirable to have watersoluble sensitisers. The use of water-soluble sensitisers such as sulfonated zinc, aluminium, gallium and iron complexes of phthalocyanines ${ }^{14}$ as photosensitisers $(\mathrm{P})$ has been reported for the photodegradation of 4-chorophenol ${ }^{14,22}$ and atrazine. ${ }^{23} \mathrm{In}$ these photosensitised oxidation reactions, two possible mechanisms may be involved: Type I mechanism involving electron or hydrogen transfer ${ }^{24}$ or Type II mechanism involving formation of singlet oxygen, ${ }^{1} \mathrm{O}_{2}$, by energy transfer from the triplet state of the sensitiser, ${ }^{3} \mathrm{P} *$ to molecular oxygen, ${ }^{3} \mathrm{O}_{2}$, and subsequent reaction of singlet oxygen with the substrate.

In this work we report the synthesis of water-soluble iron meso-tetrakis(2,6-dichloro-3-sulfophenyl)porphyrin (FeTDCPPS), 1, and its efficient application as photosensitiser in the photooxidation of 4-chlorophenol, taken as a model compound. Kinetic and mechanistic details will be discussed.

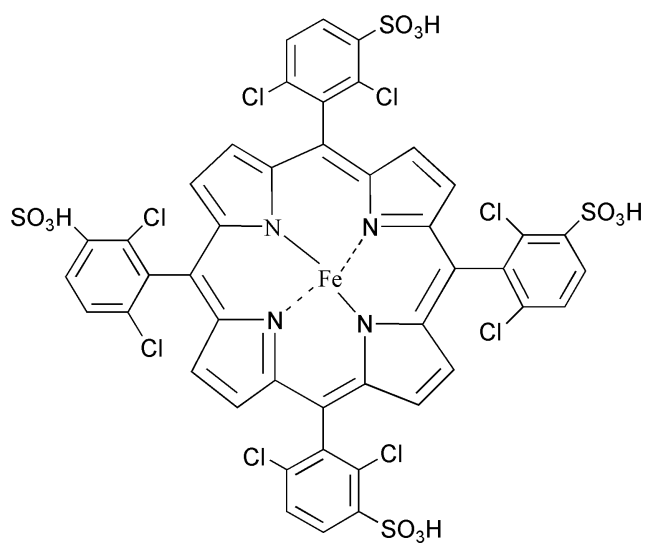

1 


\section{Experimental}

\section{Chemicals}

4-Chlorophenol (4-CP) (Aldrich) 2, p-benzoquinone (BQ) 3 (Aldrich Chem, p.a.), p-hydroquinone (HQ) 4 (Merck, p.a.), sodium azide $\left(\mathrm{NaN}_{3}\right)$ (Aldrich) and methanol (HPLC analysis grade, Merck) were used as received without further purification. All solvents used in the synthesis of the photosensitiser were purified before use. Solutions were prepared with doubly distilled water, either equilibrated with air or bubbled with argon for $30 \mathrm{~min}$ at room temperature.

\section{Synthesis of the photosensitiser}

The photosensitiser iron meso-tetrakis(2,6-dichloro-3-sulfophenyl)porphyrin, $\mathbf{1}$, was synthesised according to the method described by Gonsalves and Pereira. ${ }^{25,26}$ In this, the dichlorobenzaldehyde $(10 \mathrm{mmol})$ was dissolved in a mixture of acetic acid $(75 \mathrm{ml})$ and nitrobenzene $(50 \mathrm{ml})$ and the temperature was raised to $120^{\circ} \mathrm{C}$. Pyrrole $(0.7 \mathrm{ml})$ was then added. The temperature was kept constant for $1 \mathrm{~h}$. The solution was then allowed to cool to room temperature to give crystals of the product porphyrin, which were filtered off and dried, resulting in 5\% of meso-tetrakis(2,6-dichlorophenyl)porphyrin (TDCPP). ${ }^{1} \mathrm{H}$ $\operatorname{NMR}\left(\mathrm{CDCl}_{3}\right) \delta: 8.62(\mathrm{~s}, 8 \mathrm{H}), 7.68(\mathrm{~m}, 12 \mathrm{H}),-2.59(\mathrm{~s}, 2 \mathrm{H}) ; \mathrm{MS}$ (FAB), $m / z$ 887-905 ([M $+\mathrm{H}]^{+}, \mathrm{Cl}$ isotopes). Further details of the characterisation has been reported elsewhere. ${ }^{25}$

TDCPP $(100 \mathrm{mg})$ was then stirred with neat chlorosulfonic acid $(6 \mathrm{ml})$ at $100{ }^{\circ} \mathrm{C}$ for $3 \mathrm{~h}$. After separation by precipitation with ice, meso-tetrakis(2,6-dichloro-3-chlorosulfonylphenyl)porphyrin was obtained in $85 \%$ yield. ${ }^{1} \mathrm{H}$ NMR $\left(\mathrm{CDCl}_{3}\right) \delta: 8.65$ (s, $8 \mathrm{H}), 8.60(\mathrm{~d}, 4 \mathrm{H}, J=8.6 \mathrm{~Hz}), 8.05(\mathrm{~d}, 4 \mathrm{H}, J=8.6 \mathrm{~Hz}),-2.4$ (s, 2H); MS (FAB), $m / z 1279\left([\mathrm{M}+\mathrm{H}]^{+}\right)$. Further details of the characterisation has been reported elsewhere. ${ }^{26}$

Metallation of this porphyrin was achieved by refluxing it with iron(II) sulfate in an inert atmosphere in $N, N$-dimethylformamide. ${ }^{27}$ The reaction was monitored by UV-visible absorption spectroscopy and was stopped when the characteristic four Q bands of the free porphyrin disappeared and were replaced by the metalloporphyrin spectrum.

The final step consisted of the hydrolysis of the chlorosulfonated porphyrin $(80 \mathrm{mg})$ with water $(120 \mathrm{ml})$ in the presence of oxygen for $20 \mathrm{~h}$ to give the corresponding iron meso-tetrakis(2,6-dichloro-3-sulfophenyl)porphyrin, $\mathbf{1}$. Although we were not able to specifically determine the oxidation state of iron, indications that it is iron(III) come from changes in the UV-visible absorption spectrum when hydroxide or cyanide ions are added, and also the fact that in flash photolysis studies its triplet state is able to oxidise 4-chlorophenol Support comes from the literature on reactions between iron(II) salts and free-base porphyrins in aerated solutions leading to the corresponding iron(III) porphyrins. ${ }^{28}$

\section{Continuous photolysis}

Continuous irradiation of an aerated solution of FeTDCPPS 1 and 4-CP 2 was carried out using monochromatic light from a xenon lamp $(1600 \mathrm{~W})$ filtered with a grating monochromator set at $340 \mathrm{~nm}$. Where necessary, solutions were deaerated by bubbling with argon for $30 \mathrm{~min}$ before irradiation. The incident light intensity of the xenon lamp was determined by chemical actinometry using a solution of potassium ferrioxalate ${ }^{29}$ $\left(I_{0}=1.97 \times 10^{15}\right.$ photons $\left.\mathrm{cm}^{-2} \mathrm{~s}^{-1}\right)$. In a typical experiment an aerated aqueous solution of $2\left(6.1 \times 10^{-4} \mathrm{M}\right)$ and $\mathbf{1}\left(3.2 \times 10^{-4}\right.$ M) was added to a quartz cell $(1 \mathrm{~cm}$ pathlength), which was then irradiated. The reaction was monitored by UV-visible spectroscopy using a Shimadzu UV-2010 spectrophotometer and also by HPLC analysis. The $\mathrm{pH}$ of solutions was carefully controlled during the irradiation time using a Crison micro-pH 2000 apparatus. In addition, for mechanistic studies, an aerated solution of photosensitiser $1\left(3.2 \times 10^{-4} \mathrm{M}\right)$ and 4-CP 2 $\left(6.1 \times 10^{-4} \mathrm{M}\right)$ was irradiated at $340 \mathrm{~nm}$ in the presence of sodium azide $\left(1 \times 10^{-3} \mathrm{M}\right)$.

\section{HPLC analysis}

Analysis of degradation products of 4-CP was made using a HPLC Waters 540 liquid chromatography system equipped with a UV-visible photodiode array detector (Waters 990) with detection set at $280 \mathrm{~nm}$. The formation of the photoproducts BQ 3 and HQ 4 was monitored against external standards. A reverse phase Waters Spherisorb $5 \mu \mathrm{m}$ ODS $4.6 \times 250 \mathrm{~mm}$ column (Analytical Cartridge) was used with a mixture of $\mathrm{MeOH}-\mathrm{H}_{2} \mathrm{O}(60: 40 \mathrm{v} / \mathrm{v})$ as eluent in isocratic mode with a flow rate of $1 \mathrm{ml} \mathrm{min}^{-1}$

\section{Time-resolved flash photolysis studies}

The transient absorption spectra of the triplet state of the photosensitiser 1, the kinetics of its decay, and quenching with oxygen were measured on an Applied Photophysics LKS 60 nanosecond laser flash photolysis kinetic spectrometer using the third harmonic $(355 \mathrm{~nm})$ of a Quanta Ray GCR 130-01 $\mathrm{Nd} / \mathrm{YAG}$ laser for excitation. The transient absorbance spectra at preselected wavelengths were monitored by a detection system consisting of a pulsed xenon lamp $(150 \mathrm{~W})$, monochromator and photomultiplier. The signal from the photomultiplier was digitalised by an oscilloscope. Full details are given elsewhere. ${ }^{38}$ The concentration of the photosensitiser 1 was calculated to have maximum absorbance around 0.2-0.4 at the laser wavelength. For studying the effect of oxygen as quencher of the excited state of the photosensitiser $\mathbf{1}$, aqueous solutions of FeTDCPPS were studied with air $\left(\left[\mathrm{O}_{2}\right]=2.8 \times 10^{-4}\right.$ $\mathrm{M}){ }^{30}$ saturated with oxygen $\left(\left[\mathrm{O}_{2}\right]=1.4 \times 10^{-3} \mathrm{M}\right)$ and deaerated with argon for $30 \mathrm{~min}$. The effect of 4-CP as a quencher of the excited state of the photosensitiser 1 was also studied in deaerated solutions. The singlet oxygen quantum yield was measured by Dr S. Navaratnam (North East Wales Institute, UK) using a previously described time-resolved phosphorescence system, which uses a $\mathrm{Nd} / \mathrm{YAG}$ laser for excitation and photodiode for detection. ${ }^{31}$ The standard used was an aqueous solution of meso-tetrakis(4-sulfophenyl)porphyrin, TPPS $(\phi=0.62)$.

\section{Results and discussion}

\section{Synthesis of the photosensitiser}

Although water-soluble sulfonated meso-aryl porphyrins have frequently been synthesised by direct reaction of strong sulfuric acid and the desired precursor porphyrin, ${ }^{32}$ the use of chlorosulfonic acid in the present study has the advantage that it is more efficient, and the chlorosulfonyl porphyrin formed is very easy to isolate from the reaction medium, simply by addition of ice. The precipitate formed was extracted with dichloromethane and purified by silica gel column chromatography using dichloromethane as eluent. The iron complex of the meso-tetrakis(2,6-dichloro-3-sulfophenyl)porphyrin was prepared using the $N, N$-dimethylformamide method, ${ }^{27}$ where the porphyrin was dissolved in DMF and iron(II) sulfate was added (1:1). The formation of the complex was monitored by measuring the absorption spectrum and the bands at 429, 516, 555, 581 and $636 \mathrm{~nm}$ change to 417,518 and $586 \mathrm{~nm}$. The final step involved hydrolysis of the sulfonyl chloride by refluxing the iron(III) complex with water for $20 \mathrm{~h}$, giving after solvent evaporation, the photosensitiser 1 in $80 \%$ yield. A typical metalloporphyrin visible spectrum was observed: solvent $\left(\mathrm{H}_{2} \mathrm{O}\right) \lambda / \mathrm{nm}\left(\varepsilon / \mathrm{M}^{-1}\right.$ $\left.\mathrm{cm}^{-1}\right)$ : $417\left(3.3 \times 10^{5}\right), 518\left(8.0 \times 10^{3}\right), 586\left(4 \times 10^{3}\right)$.

\section{Continuous irradiation}

On irradiation of an aerated solutions of 4-CP $2\left(6.1 \times 10^{-4} \mathrm{M}\right)$ in the presence of the photosensitiser $1\left(3.2 \times 10^{-4} \mathrm{M}\right)$ at 
$340 \mathrm{~nm}$ significant changes in the UV-visible spectra were observed. New bands were observed in the $240-300 \mathrm{~nm}$ region. However, 4-CP and the photoproducts absorb in the same wavelength range, such that it is not possible to follow the extent of transformation simply from changes in the UV spectra. For quantitative measurements of photoconversion and product formation HPLC analysis was used.

When irradiation of 4-CP and the photosensitiser 1 was performed in the presence of oxygen the main photooxidation photoproduct was $p$-benzoquinone $3\left(\lambda_{\max }=245 \mathrm{~nm}\right)(33 \%)$ although some $p$-hydroquinone $4\left(\lambda_{\max }=288 \mathrm{~nm}\right)(6 \%)$ was also observed (Scheme 1). This is similar to what is reported for the degradation of 4-CP and related phenols in the presence of phthalocyanines and other photosensitisers. ${ }^{4,33-39}$

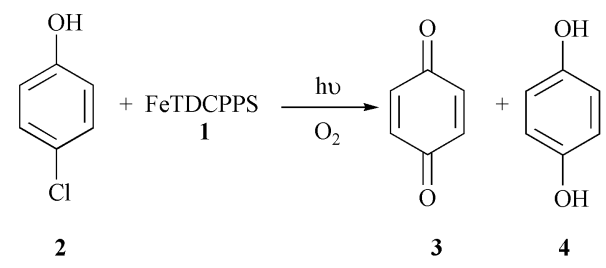

Scheme 1

The formation of the dimeric photoproducts $2,4^{\prime}$-dihydroxy5-chlorobiphenyl $\left(\lambda_{\max }=257\right.$ and $\left.295 \mathrm{~nm}\right)$ and 2,2'-dihydroxy$5,5^{\prime}$-dichlorobiphenyl $\left(\lambda_{\max }=280 \mathrm{~nm}\right)$ was also observed, in agreement with previous literature results for photodegradation of 4-CP with photooxidants. ${ }^{37,38}$ However, the dimeric species suffer further oxidation. Although their oxidation products were not characterised, increase light scattering in the UVvisible absorption spectra, at long irradiation times, confirms the formation of insoluble compounds.

Upon photolysis of deaerated solutions under the same conditions, the main photoproduct obtained was $p$-hydroquinone 4 , in agreement with previous reports on photolysis of 4-CP using different sensitisers. ${ }^{15,39}$

Upon direct photolysis at $340 \mathrm{~nm}$ of aqueous solutions of 4-CP $\left(3.2 \times 10^{-4} \mathrm{M}\right)$, in the presence of oxygen and without sensitiser, no photodegradation was observed after $3 \mathrm{~h}$ of irradiation.

We believe that the formation of $p$-benzoquinone, $\mathbf{3}$, is mainly due to the reaction of singlet oxygen with 4-CP while the formation of hydroquinone, $\mathbf{4}$, and dimeric photoproducts can be explained by electron transfer from 4-CP to the triplet state of the sensitiser with concomitant formation of the 4-chlorophenoxyl radical followed by $\mathrm{HO}$ addition or dimerisation, respectively.

The kinetic profiles were studied of photodegradation of 4-CP with photosensitiser $\mathbf{1}$ and of photoproduct $\mathbf{3}$ and $\mathbf{4}$ formation, in aerated solution, following continuous irradiation with monochromatic $340 \mathrm{~nm}$ light. The disappearance of 4-CP with irradiation time follows first order kinetics with a rate constant of $k=9.5 \times 10^{-5} \mathrm{~s}^{-1}$ and was accompanied by formation of benzoquinone and hydroquinone, Fig. 1.

Some metalloporphyrin photodegradation was observed. This, together with consumption of oxygen in the reaction mixture, may explain the fact that only $65 \%$ conversion of the chlorophenol was observed. Other metalloporphyrins, with higher photostability are currently under study.

Upon photolysis of aerated solution of the photosensitiser 1 and 4-CP 2 in the presence of sodium azide $\left(1 \times 10^{-3} \mathrm{M}\right)$, no formation of the photoproduct 3 (BQ) was observed. Azide ion is known to be a selective ${ }^{1} \mathrm{O}_{2}\left({ }^{1} \Delta_{\mathrm{g}}\right)$ singlet oxygen quencher, ${ }^{40}$ strongly suggesting that $\mathrm{BQ}$ formation results from reaction with singlet oxygen.

\section{Laser flash photolysis experiments}

The kinetic behaviour of transient species was monitored by nanosecond laser flash photolysis. Following excitation at 355

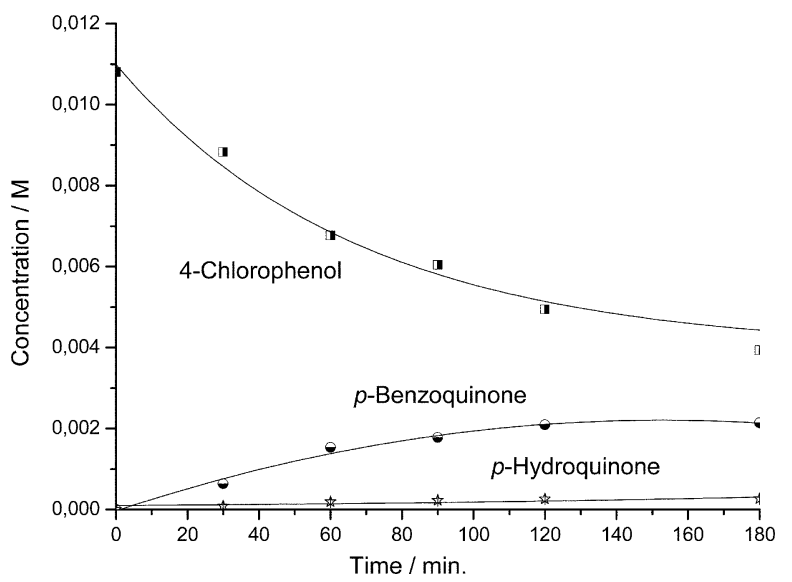

Fig. 1 HPLC analysis of the photosensitised degradation of 4-CP and the formation of the photoproducts $p$-benzoquinone and $p$-hydroquinone as a function of time.

$\mathrm{nm}$ of an aqueous solution of $\mathbf{1}\left(6.2 \times 10^{-4} \mathrm{M}\right)$ in the presence of oxygen, a transient absorption was observed between 300 and $600 \mathrm{~nm}$, with a maximum at $460 \mathrm{~nm}$, Fig. 2. This is identified as the sensitiser triplet state (T-T) absorption, in agreement with flash photolysis studies on related systems. ${ }^{41}$ No other transient species were found.

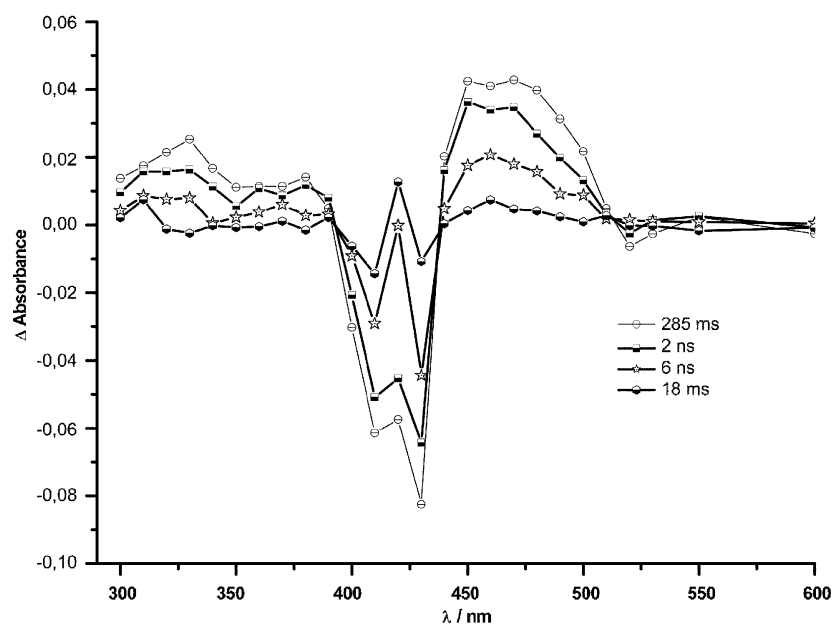

Fig. 2 Transient absorption spectra observed following laser flash photolysis at $355 \mathrm{~nm}$ of a nitrogen-saturated solution of sensitiser $\mathbf{1}$ in water.

Oxygen is a good quencher of triplet excited states. The lifetimes of the triplet state of the photosensitiser 1 were determined at $460 \mathrm{~nm}$ in aerated $(4.70 \mu \mathrm{s})$ and nitrogen saturated $(378 \mu \mathrm{s})$ solutions. The bimolecular quenching rate constant $\left(k_{\mathrm{q}}\right)$ for quenching of the triplet state of FeTDCPPS by molecular oxygen $\left({ }^{3} \mathrm{O}_{2}\right)$ in aqueous solutions is $7.25 \times 10^{8} \mathrm{M}^{-1} \mathrm{~s}^{-1}$, which is comparable to literature values for related porphyrins. $^{42}$ This is considerably lower than the diffusion controlled rate in water $\left(9.8 \times 10^{9} \mathrm{M}^{-1} \mathrm{~s}^{-1}\right)$, in agreement with the studies of Porter and co-workers, ${ }^{43}$ who suggested that for quenching of triplet states by molecular oxygen via an energy transfer mechanism, $k_{\mathrm{q}} \approx 1 / 9 k_{\text {diffusion. }}$. This supports the idea that quenching of the triplet state $\left(\mathrm{T}_{1}\right)$ of the photosensitiser 1 by molecular oxygen occurs by energy transfer with formation of the reactive species singlet oxygen $\left({ }^{1} \mathrm{O}_{2}\right)$

$$
\text { FeTDCPPS }\left(\mathrm{T}_{1}\right)+{ }^{3} \mathrm{O}_{2} \longrightarrow \text { FeTDCPPS }\left(\mathrm{S}_{0}\right)+{ }^{1} \mathrm{O}_{2}
$$

To confirm this, time-resolved measurements were carried out to detect the singlet oxygen phosphorescence. Upon excitation at $355 \mathrm{~nm}$ of aerated solutions of sensitiser $\mathbf{1}$ in water, singlet oxygen phosphorescence was observed at $1270 \mathrm{~nm}$. 
Using TPPS as standard, a singlet oxygen yield of $\Phi_{\Delta} \approx 1$ was observed. More details will be reported elsewhere. Singlet oxygen is known to react with $4-\mathrm{CP}^{44}$ with a rate $6.0 \times 10^{6} \mathrm{M}^{-1} \mathrm{~s}^{-1}$, and the above results support the idea that the photosensitised degradation of 4-CP by 1 involves, at least in part, reaction with singlet oxygen.

Formation of quinones has previously been reported in the reaction between singlet oxygen and phenols or naphthols. ${ }^{21,36}$ This reaction is suggested to proceed via 1,4-cycloaddition followed by breakdown of the intermediate endoperoxide. ${ }^{36}$

However, the reaction in the absence of oxygen suggests another pathway may also be involved. To evaluate the direct reaction between 4-CP and the triplet state of the photosensitiser 1, flash photolysis experiments were carried out with $355 \mathrm{~nm}$ excitation on deaerated aqueous solutions of FeTDCPPS with different concentrations of 4-CP, with sensitiser absorption monitored at $460 \mathrm{~nm}$. Decay of the triplet absorption was more rapid in the presence of the phenol, and from the study of the pseudo-first-order rate constant $\left(k_{\text {obs }}\right)$ as a function of 4-CP concentration, Fig. 3, the kinetics were found to follow the rate law

$$
k_{\mathrm{obs}}=k_{0}+k_{\mathrm{q}}[4-\mathrm{ClPh}]
$$

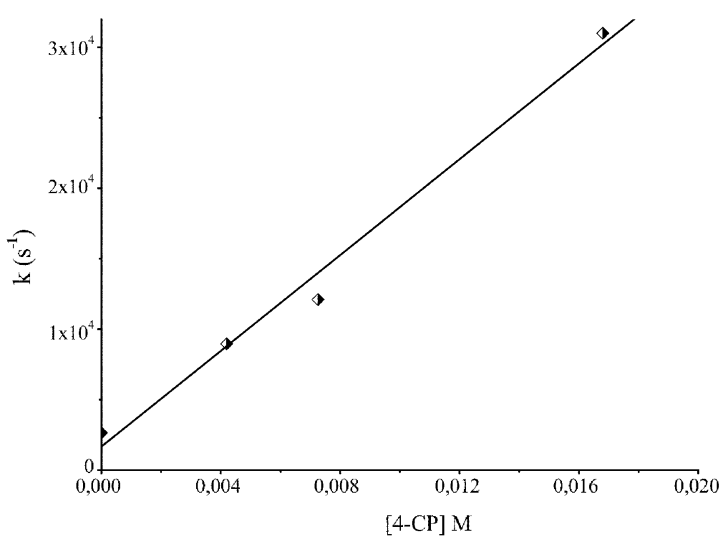

Fig. 3 Kinetic plot of the rate of decay of the triplet state of sensitiser $\mathbf{1}$ as a function of 4-chlorophenol concentration.

From the slope of this, a bimolecular quenching rate constant, of reaction of the triplet state of the photosensitiser 1 with 4-CP of $k_{\mathrm{q}}=1.68 \times 10^{6} \mathrm{M}^{-1} \mathrm{~s}^{-1}$ was determined.

This confirms that reaction between the triplet state of $\mathbf{1}$ and 4-CP occurs in parallel with singlet oxygen formation. However, for the reaction conditions employed in this study, this is likely to be less important than the sensitised photodegradation of 4-CP by singlet oxygen.

\section{Conclusions}

A water soluble metal complex, iron meso-tetrakis(2,6-dichloro3 -sulfophenyl)porphyrin, has been synthesised, and used as photosensitiser for the degradation of 4-chlorophenol. Benzoquinone and hydroquinone have been identified as the main products in aerated aqueous solution. Studies using azide as quencher, direct observation of the quenching of the porphyrin triplet state by molecular oxygen, and detection of singlet oxygen phosphorescence suggest that the dominant mechanism of quinone formation involves reaction of singlet oxygen with the chlorophenol. However, the triplet state of the quencher is also quenched by the phenol, and this process may provide a second, but less important, route to 4-chlorophenol degradation

\section{Acknowledgements}

Financial support for the collaboration between ClermontFerrand and Coimbra by ICCTI/GRICES and CNRS is gratefully acknowledged. We also thank FCT, POCTI and FEDER for further funding and $\mathrm{Dr} \mathrm{S}$. Navaratnam for kindly carrying out singlet oxygen phosphorescence measurements.

\section{References}

1 H. D. Burrows, M. Canle L, J. A. Santaballa and S. Seteenken, Reaction pathways and mechanisms of photodegradation of pesticides, J. Photochem. Photobiol. B: Biol., 2002, 67, 71-108.

2 H. D. Burrows, L. S. Ernestova, T. J. Kemp, Y. I. Skurlatov, A. P. Purmal and A. N. Yermakov, Kinetics and Mechanism of Photodegradation of Chlorophenols, Prog. React. Kinet., 1998, 23, 145-207.

3 M. I. Silva, H. D. Burrows, M. G. Miguel and S. J. Formosinho, Tris-2,2'-Bipyridylruthenium(II) Peroxydisulfate as a Photosensitizer in the Oxidative Degradation of 4-Chlorophenol, Ber. Bunsenges. Phys. Chem., 1996, 100, 138-143a.

4 E. L. Kochany and J. R. Bolton, Flash Photolysis/HPLC Applications. 2. Direct photolysis vs hydrogen peroxide mediated photodegradation of 4-Chlorophenol as studied by a flash photolysis/HPLC technique, Environ. Sci. Technol., 1992, 26, 259262

5 M. Nowakowska and M. Kepczynski, Polymeric photosensitizers. 2. Photosensitized oxidation of phenol in aqueous solution, J. Photochem. Photobiol. A: Chem., 1997, 116, 251-256.

6 M. Sarakha, H. D. Burrows and M. Bolte, Selective oxidation of meta- and para-phenylphenol photosensitized by $\left[\mathrm{Co}\left(\mathrm{NH}_{3}\right)_{5} \mathrm{~N}_{3}\right]^{2+}$ in aqueous solution, J. Photochem. Photobiol. A: Chem., 1996, 97, 81-86.

7 Yu. I. Skurlatov, L. S. Ernestova, E. V. Vichutinskaya, D. P. Samsonov, I. V. Semenova, I. Ya. Rod'ko, V. O. Shvidky, R. I. Pervunina and T. J. Kemp, Photochemical transformation of polychlorinated phenols, J. Photochem. Photobiol. A: Chem., 1997, 107, 207-213

8 M. Sarakha, M. Bolte and H. D. Burrows, The photo-oxidation of 2,6-dimethylphenol and monophenylphenols by uranyl ion in aqueous solution, J. Photochem. Photobiol. A: Chem., 1997, 107, 101-106.

9 J. C. D'Oliveira, G. Al-Sayyed and P. Pichat, Photodegradation of 2- and 3-Chlorophenol in $\mathrm{TiO}_{2}$ aqueous suspensions, Environ. Sci. Technol., 1990, 24, 990-996.

10 M. Sarakha and M. Bolte, Transformation of 2,6-dimethylphenol photoinduced by excitation of $\left[\mathrm{Co}\left(\mathrm{NH}_{3}\right)_{5} \mathrm{~N}_{3}\right]^{2+}$ at $365 \mathrm{~nm}$, J. Photochem. Photobiol. A: Chem., 1996, 97, 87-92.

11 O. Legrini, E. Oliveiros and A. M. Braun, Photochemical processes for water treatment, Chem. Rev., 1993, 93, 671-698.

12 H. Honigsmann, G. Jori and A. R. Young, The Fundamental Bases of Phototherapy, OEMF, Milan, 1996.

13 M. Tarr and D. P. Valenzo, Singlet oxygen: the relevance of extracellular production mechanisms to oxidative stress in vivo, Photochem. Photobiol. Sci., 2003, 355-361.

14 G. Lente and J. H. Espenson, Photoaccelerated oxidation of chlorinated phenols, Chem. Commun., 2003, 1162-1163.

15 K. Ozoemena, N. Kuznetsova and T. Nyokong, Photosensitised transformation of 4-chlorophenol in the presence of aggregated and non-aggregated metallophthalocyanines, J. Photochem. Photobiol. A: Chem., 2001, 139, 217-224.

16 W. Spiller, D. Wöhrle, G. S. Ekloff, W. T. Ford, G. Schneider and J. Stark, Photo-oxidation of sodium sulfide by sulfonated phthalocyanines in oxygen-saturated aqueous solutions containing detergents or latexes, J. Photochem. Photobiol. A: Chem., 1996, 95, $161-173$.

17 J. A. S. Cavaleiro, H. Görner, P. S. S. Lacerda, J. G. MacDonald, G. Mark, M. G. P. M. S. Neves, R. S. Nohr, H. P. Schuchmann, C. von Sonntag and A. C. Tomé, Singlet oxygen formation and photostability of meso-tetraarylporphyrin derivatives and their copper complexes, J. Photochem. Photobiol. A: Chem., 2001, 144, 131-140.

18 J. Mosinger and Z. Micka, Quantum yields of singlet oxygen of metal complexes of meso-tetrakis(sulfonatophenyl) porphyrin, J. Photochem. Photobiol. A: Chem., 1997, 107, 77-82.

19 M. Pineiro, A. L. Carvalho, M. M. Pereira, A. M. d'A. R. Gonsalves, L. G. Arnaut and S. J. Formosinho, Photoacoustic measurements of porphyrin triplet-state quantum yields and singletoxygen efficiencies, Chem. Eur. J., 1998, 4, 2299-2307.

20 E. G. Azenha, A. C. Serra, M. Pineiro, M. M. Pereira, J. S. de Melo, L. G. Arnaut, S. J. Formosinho and A. M. d'A. R. Gonsalves, Heavy-atom effects on metalloporphyrins and polyhalogenated porphyrins, Chem. Phys., 2002, 280, 177-190. 
21 D. Murtinho, M. Pineiro, M. M. Pereira, A. M. d'A. R. Gonsalves, L. G. Arnaut, M. G. Miguel and H. D. Burrows, Novel porphyrins and a chlorin as efficient singlet oxygen sensitisers for photooxidation of naphthols or phenols to quinones, J. Chem. Soc., Perkins Trans. 2, 2000, 2441-2447.

22 R. Gerdes, D. Wöhrle, W. Spiller, G. Schneider, G. Schnurpfeil and G. S. Ekloff, Photo-oxidation of phenol and monochlorophenols in oxygen-saturated aqueous solutions by different photosensitizers, J. Photochem. Photobiol. A: Chem., 1997, 111, 65-74.

23 V. Héquet, P. Le Cloirec, C. Gonzalez and B. Meunier, Photocatalytic degradation of atrazine by porphyrin and phthalocyanine complexes, Chemosphere, 2000, 41, 379-386

24 C. S. Foote, Definition of type I and type II photosensitized oxidation, Photochem. Photobiol., 1991, 54, 659.

25 A. M. d'A. R. Gonsalves, Jorge M. T. B. Varejão and M. M. Pereira Some new aspects related to the synthesis of meso-substituted porphyrins, J. Heterocycl. Chem., 1991, 28, 635-638.

26 A. M. d'A. R. Gonsalves, R. A. W. Johnstone, M. M. Pereira, A. M P. De Santana, A. C. Serra, A. J. F. N. Sobral and P. A. Stocks, New procedures for the synthesis and analysis of 5,10,15,20-tetrakis(sulfophenyl)porphyrins and Derivatives Through Chlorosulfonation, Heterocycles, 1996, 43, 829-838.

27 A. D. Adler, F. R. Longo, F. Kampas and J. Kim, On the preparation of metalloporphyrins, J. Inorg. Nucl. Chem., 1970, 32, 2443-2445.

28 K. M. Smith, in Porphyrins and Metalloporphyrins, Elsevier, Scientific Pub., Amesterdam, 1975, pp. 803-804.

29 C. G. Hatchard and C. A. Parker, A new sensitive chemical actinometer. 2. Potassium ferrioxalate as a standard chemical actinometer, Proc. R. Soc. London, Ser. A, 1956, 235, 518-536.

$30 \mathrm{~S}$. L. Murov, I. Carmichael and G. L. Hug, in Handbook of Photochemistry, Marcel Dekker, New York, 1993, 2nd edn., p. 293.

31 S. Navaratnam, I. Hamblett and H. H. Tonnesen, Photoreactivity of biologically active compounds. XVI. Formation and reactivity of free radicals in mefloquine, J. Photochem. Photobiol. B: Biol., 2000, 56, 25-38.

32 E. B. Fleicher, J. M. Palmer, T. S. Srivastava and A. Chatterjee, Thermodynamic and kinetic properties of an iron-porphyrin system, J. Am. Chem. Soc., 1971, 93, 3162-3167.

33 K. Lang, D. M. Wagnerová and J. Brodilová, The role of excited states in photosensitized oxidation of substrates with dioxygen, J. Photochem. Photobiol. A: Chem., 1993, 72, 9-14.
34 T. Sehili, P. Boule and J. Lemaire, Photocatalysed transformation of chloroaromatic derivatives on zinc oxide III: chlorophenols, J. Photochem. Photobiol. A: Chem., 1989, 50, $117-$ 127.

35 E. L. Kochany and J. R. Bolton, Flash photolysis/HPLC method for studying the sequence of photochemical reactions: applications to 4-chlorophenol in aerated aqueous solution, J. Photochem. Photobiol. A: Chem., 1991, 58, 315-322.

$36 \mathrm{C}$. Li and M. Z. Hoffman, Oxidation of phenol by singlet oxygen photosensitized by the tris $\left(2,2^{\prime}\right.$-bipyridine $)$ ruthenium(II) ion, J. Phys. Chem. A, 2000, 104, 5998-6002.

37 G. Grabner, C. Richard and G. Köhler, formation and reactivity of 4-oxocyclohexa-2,5-dienylidene in the photolysis of 4-chlorophenol in aqueous solution at ambient temperature, J. Am. Chem. Soc., 1994, 116, 11470-11480.

38 M. Sarakha, M. Bolte and H. D. Burrows, Electron-transfer oxidation of chlorophenols by uranyl ion excited state in aqueous solution. Steady-state and nanosecond flash photolysis, J. Phys. Chem. A, 2000, 104, 3142-3149.

$39 \mathrm{~K}$. Oudjehani and P. Boule, Photoreactivity of 4-chlorophenol in aqueous solution, J. Photochem. Photobiol. A: Chem., 1992, 68, 363-373.

40 F. Wilkinson, W. P. Helman and A. B. Ross, Rate constants for the decay and reaction of the lowest excited singlet state of molecular oxygen in solution, J. Phys. Chem. Ref. Data, 1993, 22, 6631021.

41 See, for example: L. Pekkarinen and H. Linschitz, Studies on metastable states of porphyrins. II. Spectra and decay kinetics of tetraphenylporphyrin, zinc tertaphenylporphyrin and bacteriochlorophyll, J. Am. Chem. Soc., 1960, 82, 2407-2411.

42 J. C. P. Grancho, M. M. Pereira, M. da G. Miguel, A. M. Rocha Gonsalves and H. D. Burrows, Synthesis, spectra and photophysics of some free base tetrafluoroalkyl and tetrafluoroaryl porphyrins with potential applications in imaging, Photochem. Photobiol., 2002, 75, 249-256.

43 O. L. J. Gijzemann, F. Kaufman and G. Porter, Oxygen quenching of aromatic triplet states in solution. Part 1, J. Chem. Soc., Faraday Trans. 2, 1973, 69, 708-720.

44 P. G. Tratnyek and J. Hoigné, Oxidation of substituted phenols in the environment - a QSAR analysis of rate constants for reaction with singlet oxygen, Environ. Sci. Technol., 1991, 25, 15961604 